\title{
Outcomes of vitrified-warmed cleavage-stage embryo hatching after in vitro laser-assisted zona pellucida thinning in patients
}

\author{
EN-HUA WANG ${ }^{1}$, AN-CONG WANG ${ }^{2,3}$, BAO-SONG WANG $^{2}$ and BIN LI ${ }^{2}$ \\ ${ }^{1}$ Department of Genetic Teaching and Research Section, Shandong Medical College, Linyi, Shandong 276000; \\ Departments of ${ }^{2}$ Reproductive Medicine and ${ }^{3}$ Obstetrics and Gynecology, Linyi People's Hospital, \\ Linyi, Shandong 276003, P.R. China
}

Received February 18, 2016; Accepted July 8, 2016

DOI: $10.3892 / b r .2016 .716$

\begin{abstract}
The aim of the present study was to determine whether the size of the zona pellucida (ZP) thinning area by laser-assisted hatching affected the potential development of vitrified-warmed embryos. A total of 196 vitrified-warmed cleavage-stage embryos (from 49 patients, four sister embryos per patient) were used in the study, i.e., four sister embryos from each patient were randomly assigned to four groups: A control group of embryos that were not zona-manipulated (zona intact, group A); one experimental group of embryos in which a quarter of the zona pellucida was thinned using laser-assisted ZP thinning (group B); a second experimental group of embryos in which half of ZP was thinned (group C); and a third group in which two-thirds of the ZP was thinned (group D). Subsequent blastocyst development was assessed. Microscopy was performed to study the hatching process of the embryos after zona thinning. The blastocyst formation rates were $71.43 \%$ in group $A, 67.35 \%$ in group $B, 65.31 \%$ in group $C$, and $51.02 \%$ in group $\mathrm{D}$ (groups $\mathrm{B}-\mathrm{D}$ vs. group $\mathrm{A}, \mathrm{P}=0.661, \mathrm{P}=0.515$, $\mathrm{P}=0.038$, respectively). The rates of complete hatching were $30.61 \%$ in group A, $38.78 \%$ in group B, $61.22 \%$ in group C, and $48.98 \%$ in group $\mathrm{D}$ (groups $\mathrm{B}-\mathrm{D}$ vs. group $\mathrm{A}, \mathrm{P}=0.396$, $\mathrm{P}=0.002, \mathrm{P}=0.063$, respectively). For a subgroup of patients, there was a significant difference in the complete hatching in all the groups for women aged $<35$ years $(\mathrm{P}=0.011)$, and there was a significant difference in the complete hatching in all the groups for secondary infertility women $(\mathrm{P}=0.022)$. There was no significant difference in the blastocyst formation rates in the different groups of women aged $\geq 35$ years $(\mathrm{P}=0.340)$. In addition, there was no significant difference in the complete
\end{abstract}

Correspondence to: Professor An-Cong Wang, Department of Reproductive Medicine, Linyi People's Hospital, 27 Jiefang Road, Linyi, Shandong 276003, P.R. China

E-mail: ancongw12@163.com

Key words: cleavage-stage embryos, laser-assisted hatching, zona pellucida thinning, vitrification, in vitro culture hatching in the different groups among women aged $\geq 35$ years $(\mathrm{P}=0.492)$. The results of the present study showed that in vitrified-warmed embryo transfers at the cleavage-stage, and the two-thirds zona pellucida thinning group demonstrated a significantly decreased blastocyst formation rate compared with the control group, while the half zona pellucida thinning group demonstrated a significantly increased complete hatching rate compared with the control group, which may have a high value in clinical application.

\section{Introduction}

It is widely known that improving the embryo implantation rate is one of the main objectives of assisted reproductive technologies (ARTs). The most common method to achieve better results is to obtain and transfer multiple embryos. The surplus embryos produced using ARTs may be cryopreserved for subsequent use (1). The success of cryopreservation may undoubtedly increase the cumulative pregnancy rates of ARTs. However, these results appear to indicate a reduction in the clinical pregnancy and implantation rates compared with fresh embryos (2).

A glycoprotein layer, known as the zona pellucida (ZP), surrounds human embryos and permits only acrosome-intact sperm to fertilize the oocyte by blocking the entry of multiple sperm. After fertilization, the ZP compresses and shapes the embryo, protecting it from microorganisms and immune cells. At the blastocyst stage, the embryo breaks out of the $\mathrm{ZP}$ to begin the developmental process; failure at this stage can prevent implantation. Hatching of the embryo is a critical step in the sequence of physiological events that culminate in implantation. Failure to hatch, due to intrinsic abnormalities in the blastocyst or ZP, may be the main factors limiting human-assisted reproductive efficiency, and the effects of zona hardening on embryo hatching are probably one of the consequences of the process of freezing and thawing embryos (3). Therefore, artificial thinning of the zona or drilling of the zona may improve the embryo's potential and thus improve the clinical outcome of the thawing cycle. Since the 1980s, assisted hatching (AH) has been used to improve the chances of implantation during ARTs (1).

AH using a $1.48-\mu \mathrm{m}$ diode laser yields a better outcome than $\mathrm{AH}$ using mechanical or chemical methods $(4,5)$. 
However, to the best of our knowledge, no single study has been able to demonstrate sufficient evidence favourable to $\mathrm{AH}$, and the current research conclusions are not unanimous (6-13). In a large meta-analysis, Martins et al showed that laser-AH (LAH) is currently one of the best, safest and most effective AH methods (14). LAH can improve the clinical pregnancy rate of the thawing cycle. Since LAH can be divided into artificial thinning of the zona and drilling of the zona, previous findings have shown that the former is better than that the latter in vitro $(15,16)$. Hiraoka et al have shown that vitrification can increase the hardness of zona, and the embryo implantation and clinical pregnancy rates in the half $\mathrm{ZP}$ thinning FET cycle was superior to that of a quarter ZP, although these studies lacked a control group (1). However, to the best of our knowledge, no study has included a sufficient sample to properly evaluate the effect of LAH on assisted reproduction outcomes $(1,17)$. In the present study, we used vitrified frozen-thawed sister embryos and performed laser-assisted ZP thinning to reduce a quarter, a half and two-thirds area of the zona in the experimental groups.

The aim of the current study was to observe the rate of blastocyst formation and the complete hatching rate to determine which size of ZP thinning by LAH is optimal for embryonic development and to determine the best LAH method.

\section{Materials and methods}

Patients and embryos. The present study originally included 58 infertility patients who were admitted to the IVF unit of Linyi People's Hospital (Linyi, China) from May 1, 2011 to November 31, 2011, while 9 patients with $<4$ frozen-thawed embryos (grade I or II) were excluded. Among them, there were 26 women aged $<35$ years (13 in primarily infertility and 13 in secondary infertility) and 23 women aged $\geq 35$ years (11 in primarily infertility and 12 in secondary infertility). All of the patients with frozen-thawed embryos had $>4$ high quality sister embryos surviving, and each couple had succeeded in delivering at least one child. Any unused embryos were discarded. The embryonic blastomeres selected dissolved $\leq 2$ (from 49 IVF patients) frozen-thawed blastomeres on day 3 , and grade I or II embryos at the $7-10$ cell stage were selected. The embryos were scored as indicated in a previous study (18): grade I, uniform blastomere size; regular morphology; intact zona; homogeneous cytoplasm, clear, with no particle phenomenon; and embryo fragmentation of $<5 \%$. Grade II, slightly uneven blastomere size; slightly irregular morphology; cytoplasmic visible particle phenomenon; and debris of $6-20 \%$. The sister embryos from the same patient were randomly divided into four groups: a control group of embryos that were not zona-manipulated (zona intact, group A); one experimental group of embryos in which a quarter area (1/4) of the ZP was thinned using laser-assisted ZP thinning (group B); a second experimental group of embryos in which a half area (1/2) of the $\mathrm{ZP}$ was thinned (group $\mathrm{C}$ ); and a third group in which a two-thirds area (2/3) of the ZP was thinned (group D). Subsequent blastocyst development was assessed (Fig. 1). The [patients were included in the study if they met the following requirements: 24-39 years of age and a body mass index of $18-28 \mathrm{~kg} / \mathrm{m}^{2}$. The fecundities of the male partners of the patients were normal according to the World Health Organization criteria (19).

The present study was conducted at the Linyi People's Hospital (Shandong, China) and was approved by the Ethics Committee of Linyi People's Hospital. A written informed consent form was obtained from all patients.

The embryos, which were all at the 7-10 cell stage, were pooled and divided into four groups by defocusing the microscope to prevent any bias in the selection.

Warming of embryos and AH. Vitrification was performed on embryos derived from IVF or ICSI cycles. It has been shown that these two sources of embryos have no effect on their cultivation $(20-22)$.

Over $50 \%$ of the blastomeres in one embryo survived and were continuously cultured. Otherwise, the embryos were discarded. Vitrified embryos considered grade I or II embryos were warmed in the following manner: the protective cover was warmed in liquid nitrogen, and the end of the polypropylene strip was immersed directly into $1 \mathrm{ml}$ of $37^{\circ} \mathrm{C}$ $1.0 \mathrm{~mol} / \mathrm{l}$ sucrose solution for $1 \mathrm{~min}$. The embryos were then transferred into $1 \mathrm{ml}$ of $37^{\circ} \mathrm{C} 0.5 \mathrm{~mol} / 1$ sucrose solution for $3 \mathrm{~min}$ and washed twice in the base medium for $5 \mathrm{~min}$. $\mathrm{AH}$ was performed using a previously described method (23). The average thickness of the zona pellucida was calculated by the numerical values measured at the $12,3,6$, and 8 o'clock positions from the inside to the outside.

The laser system consisted of a Fertilase 1.48- $\mu \mathrm{m}$ laser, $100 \mathrm{~mW}$, operated by an Octax Eyeware digital interface (MTG, Bruckberg, Germany) and positioned on a Nikon Eclipse TE2000-U inverted microscope (Nikon Instruments Europe B.V., Badhoevedorp, The Netherlands).

Embryos were randomly divided into four groups, and the embryos were thawed immediately after LAH. The frozen-thawed embryos were placed in the inverted microscope at $37^{\circ} \mathrm{C}$, and the embryos were fixed with a holding pipette at the 9 o'clock position. The thinning procedure was standardized during pilot experiments to establish a smooth lasered area. A 5- $\mu \mathrm{m}$ hole was formed in the zona pellucida using one laser shot. The laser thinning was initiated at the 12 o'clock position, and consecutive irradiations were performed untill the 3 o'clock position (quarter thinning, group B), the 6 o'clock position (half thinning, group $\mathrm{C}$ ) or the 8 o'clock position (two-thirds thinning, group D) at a depth of $60-80 \%$ of the zona pellucida thickness (Fig. 2).

After LAH, the embryos were washed several times and transferred to $\mathrm{G} 2$ medium. The embryos were then cultured in an atmosphere of $6 \% \mathrm{CO}_{2}, 5 \% \mathrm{O}_{2}$ and balance $\mathrm{N}_{2}, \mathrm{pH} 7.32$ at $37^{\circ} \mathrm{C}$ using a Labotect C200 incubator (Labotect LaborTechnik-Göttingen GmbH, Göttingen, Germany). In the control group, the same conditions were performed directly after the embryos were thawed. Any manipulations were performed at room temperature $\left(22-23^{\circ} \mathrm{C}\right)$. In the present study, observations were performed on day 5, at 6:00 a.m. and in the afternoon. Complete blastocysts spreading (beyond a score of $4 \mathrm{BB}$ ) was recorded four times. Observation was continually performed on day 6, at 7:00 a.m. and in the afternoon in order to record whether the blastocyst had completely hatched. 


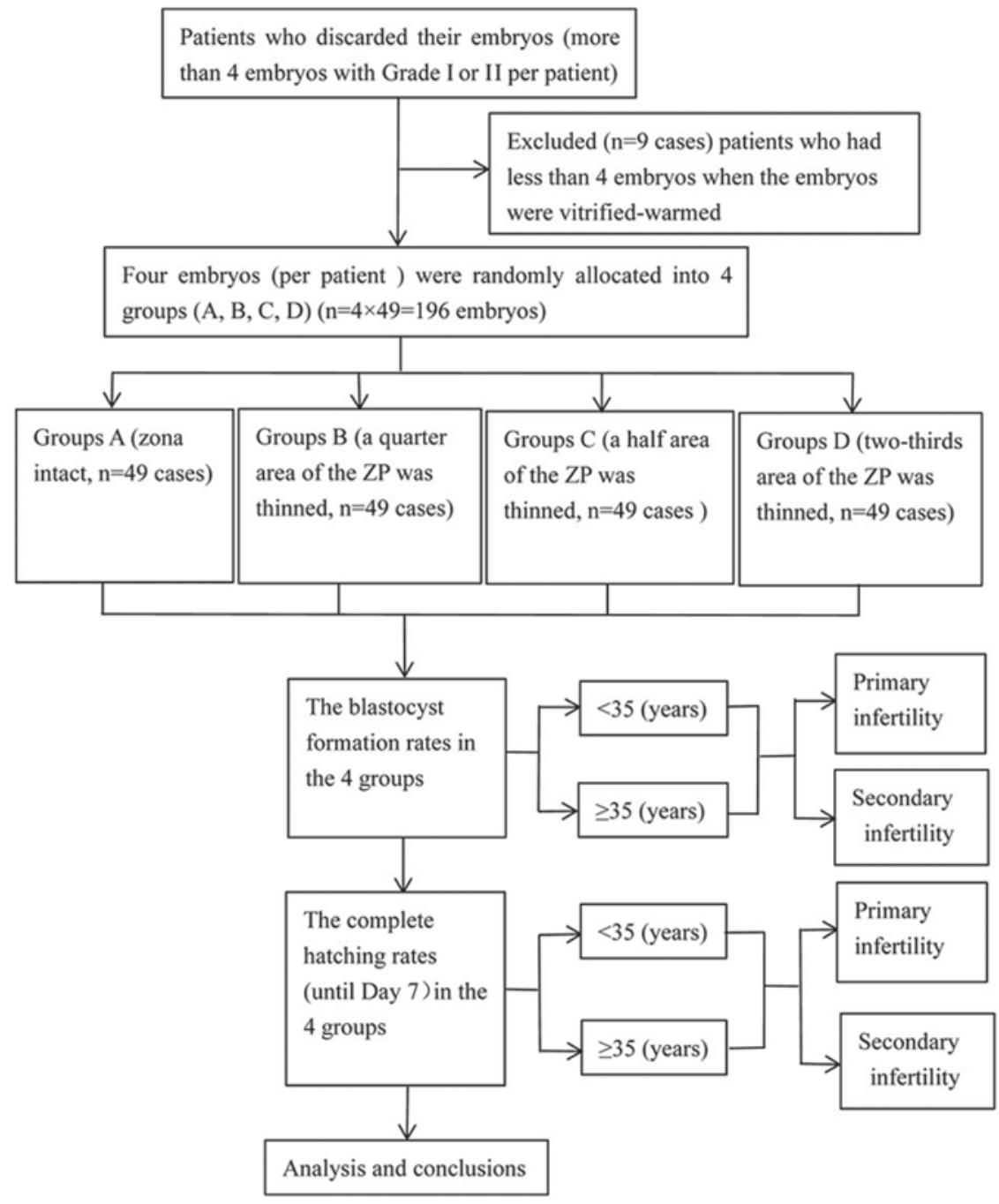

Figure 1. Flow diagram of embryos throughout each stage of the study.
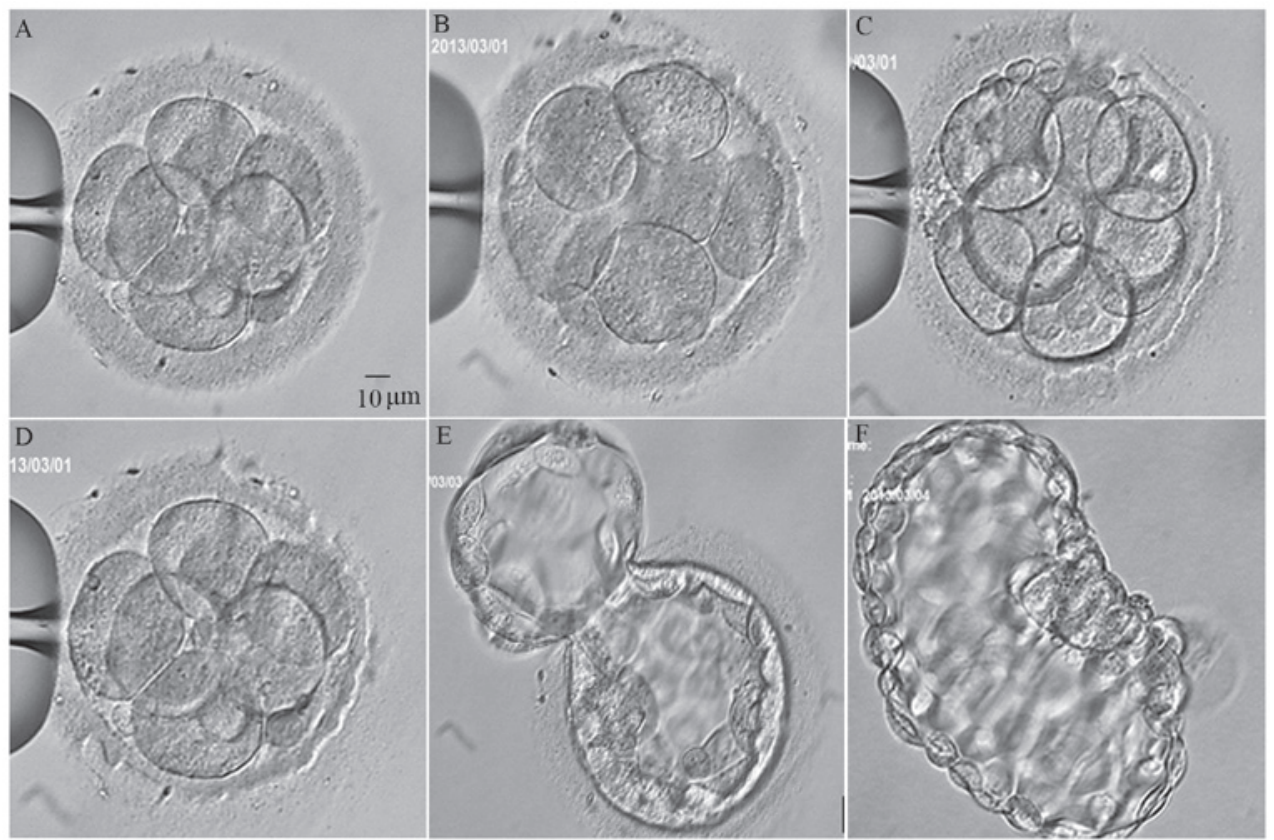

Figure 2. Vitrified-warmed human cleavage-stage embryos and the hatching of the embryos (A) stabilized with a holding pipette with the zona intact, (B) after quarter ZP thinning using laser-assisted hatching, (C) after half ZP thinning using laser-assisted hatching, (D) after two-thirds ZP thinning by laser-assisted hatching, (E) partial hatching of the embryos, and (F) complete hatching. Bar, $10 \mu \mathrm{m}$. ZP, zona pellucida. 
Table I. Rate of blastocyst formations in the different groups.

\begin{tabular}{lcccc}
\hline Groups & $\begin{array}{c}\text { No. of } \\
\text { blastocyst } \\
\text { formation }\end{array}$ & $\begin{array}{c}\text { No. of } \\
\text { blastocyst } \\
\text { non-formation }\end{array}$ & $\begin{array}{c}\text { Rate of } \\
\text { blastocyst } \\
\text { formation }\end{array}$ & P-value \\
\hline Group A & 35 & 14 & $71.43 \%$ & - \\
Group B & 33 & 16 & $67.35 \%$ & $0.661^{\mathrm{a}}$ \\
Group C & 32 & 17 & $65.31 \%$ & $0.515^{\mathrm{b}}$ \\
Group D & 25 & 24 & $51.02 \%$ & $0.038^{\mathrm{c}}$ \\
\hline
\end{tabular}

${ }^{\mathrm{a}}$ Group B comparison with control group (group A) (67.35 vs. $71.43 \%$ ). ${ }^{\mathrm{b}}$ Group C comparison with control group (group A) (65.31 vs. $71.43 \%$ ). ${ }^{\mathrm{c} G r o u p ~ D ~ c o m p a r i s o n ~ w i t h ~ c o n t r o l ~ g r o u p ~(g r o u p ~ A) ~(51.02 ~ v s . ~} 71.43 \%$ ). Values with $\mathrm{P}<0.05$ were considered statistically significant.

Statistical analysis. SPSS 23.0 software for Windows was used for statistical analysis (SPSS, Inc., Chicago, IL, USA). The data were reported as the mean \pm standard deviation (SD). The differences in the variables between the groups were statistically analysed using the Student's t-test or one-way ANOVA. For the purpose of analysis of the categorical data (e.g., blastocyst formation rate, and hatching rate), significant differences were evaluated using the Chi-square test when appropriate. $\mathrm{P}<0.05$ was considered statistically significant.

\section{Results}

Patient information. Fifty-eight patients were initially included in the study, and 9 patients with $<4$ frozen-thawed embryos (grade I or II) were excluded. A total of 196 embryos from 49 patients were eventually enrolled in the study.

The mean age for the $<35$-year women was $27.23 \pm 3.02$ $($ mean \pm SD) $(95 \%$ CI, 26.00-28.45) and the mean age of the $\geq 35$-year women was $36 \pm 1.17$ (95\% CI, 35.50-36.50) for the groups. The mean zona were $17.46 \pm 0.58,17.35 \pm 0.51$, $17.36 \pm 0.54$ and $17.58 \pm 0.42 \mu \mathrm{m}$ for groups A-D, respectively. There was no significant difference in the thickness of the four groups $(\mathrm{P}=0.088)$.

Rate of blastocyst formation and complete hatching. The blastocyst formation rates were $71.43 \%$ (35/49) in group A, $67.35 \%$ (33/49) in group B, 65.31\% (32/49) in group C, and $51.02 \%(25 / 49)$ in group D [overall group (groups B-D) comparison with group $\mathrm{A}, \mathrm{P}=0.661, \mathrm{P}=0.515, \mathrm{P}=0.038$, respectively] (Table I). The rates of complete hatching were $30.61 \%$ (15/49) in group A, 38.78\% (19/49) in group B, 61.22\% (30/49) in group $C$, and $48.98 \%$ (24/49) in group $D$ [comparison with group $\mathrm{A}, \mathrm{P}=0.396$ (group $\mathrm{B}$ vs. group $\mathrm{A}$ ), $\mathrm{P}=0.002$ (group $\mathrm{C}$ vs. group $\mathrm{A}$ ), $\mathrm{P}=0.063$ (group D vs. group $\mathrm{A}$ )] (Table II).

Blastocyst formation and complete hatching in the subgroups. The blastocyst formation rates for the subgroup of women aged $<35$ years were $73.08 \%(19 / 26)$ in group A, 69.23\% (18/26) in group B, $80.77 \%(21 / 26)$ in group C, and $53.85 \%(14 / 26)$ in group D. There was no significant difference in the blastocyst formation rates in the different groups among women aged $<35$ years $\left(\chi^{2}=4.694, \mathrm{P}=0.196\right)$. The blastocyst formation rates for
Table II. Rate of complete hatching (until day 7) in the different groups.

\begin{tabular}{lcccc}
\hline Groups & $\begin{array}{c}\text { No. of } \\
\text { complete } \\
\text { hatching }\end{array}$ & $\begin{array}{c}\text { No. of no } \\
\text { or partial } \\
\text { hatching }\end{array}$ & $\begin{array}{c}\text { Rate of } \\
\text { complete } \\
\text { hatching }\end{array}$ & P-value \\
\hline Group A & 15 & 34 & $30.61 \%$ & - \\
Group B & 19 & 30 & $38.78 \%$ & $0.396^{\mathrm{a}}$ \\
Group C & 30 & 19 & $61.22 \%$ & $0.002^{\mathrm{b}}$ \\
Group D & 24 & 25 & $48.98 \%$ & $0.063^{\mathrm{c}}$ \\
\hline
\end{tabular}

${ }^{\mathrm{a}}$ Group B comparison with control group (group A) (38.78 vs. $30.61 \%$ ). ${ }^{\mathrm{b}} \mathrm{Group} \mathrm{C}$ comparison with control group (group A) (61.22vs. $\left.30.61 \%\right)$. ${ }^{\mathrm{c}}$ Group D comparison with control group (group A) (48.98 vs. $30.61 \%$ ). Values with $\mathrm{P}<0.05$ were considered statistically significant.

the subgroup of patients aged $\geq 35$ years were $69.57 \%(16 / 23)$ in group A, 65.22\% (15/26) in group B, $47.83 \%$ (11/23) in group C, and $47.83 \%(11 / 23)$ in group D. There was no significant difference in the blastocyst formation rates in the different groups in women aged $\geq 35$ years $\left(\chi^{2}=3.357, \mathrm{P}=0.340\right)$ (Table III).

In addition, the rates of complete hatching (women aged $<35$ years) were $30.77 \%(8 / 26)$ in group A, $50 \%(13 / 26)$ in group B, 76.92\% (20/26) in group C, and 53.85\% (14/26) in group D. There was a significant difference in the complete hatching in the different groups among women aged $<35$ years $\left(\chi^{2}=11.230, \mathrm{P}=0.011\right)$. The rates of complete hatching (women aged $\geq 35$ years) were $30.43 \%$ (7/23) in group A, $26.09 \%(6 / 23)$ in group B, $43.48 \%$ (10/23) in group C, and $43.48 \%(10 / 23)$ in group D. There was no significant difference in the complete hatching in the different groups among women aged $\geq 35$ years $\left(\chi^{2}=2.410, P=0.492\right)$ (Table IV).

Blastocyst formation and complete hatching in the subgroups of patients with primary and secondary infertility. The blastocyst formation rates for the subgroup of patients with primary infertility were 58.33\% (14/24) in group A, 54.17\% (13/24) in group B, 54.17\% (13/24) in group C, and 33.33\% (8/24) in group D. There was no significant difference in the blastocyst formation rates in the different groups with primary infertility $\left(\chi^{2}=3.667, \mathrm{P}=0.300\right)$. The blastocyst formation rates for the subgroup of patients with secondary infertility was $84 \%(21 / 25)$ in group A, 80\% (20/25) in group B, 76\% (19/25) in group C, and $68 \%(17 / 25)$ in group D. There was no significant difference in the blastocyst formation rates in the different groups with secondary infertility $\left(\chi^{2}=1.976, \mathrm{P}=0.577\right)$ (Table III).

In addition, the rates of complete hatching (primary infertility) were $20.83 \%(5 / 24)$ in group A, $33.33 \%(8 / 24)$ in group B, $45.83 \%$ (11/24) in group C, and $29.17 \%$ (7/24) in group D. There was no significant difference in the complete hatching in the different groups with primary infertility women $\left(\chi^{2}=3.573, \mathrm{P}=0.311\right)$. The rates of complete hatching (secondary infertility) were $40 \%(10 / 25)$ in group A, $44 \%$ $(11 / 25)$ in group B, 76\% (19/25) in group C, and 68\% (17/25) in group D. There was a significant difference in complete hatching in the different groups among women with secondary infertility women $\left(\chi^{2}=9.588, \mathrm{P}=0.022\right)$ (Table IV). 
Table III. Blastocyst formation in the different subgroups.

\begin{tabular}{|c|c|c|c|c|c|c|}
\hline \multirow[b]{2}{*}{ Groups } & \multirow[b]{2}{*}{ Age (years) } & \multicolumn{2}{|c|}{ No. of blastocyst formation } & \multicolumn{2}{|c|}{ Failed to blastocyst formation } & \multirow[b]{2}{*}{ Total } \\
\hline & & Primary infertility & Secondary infertility & Primary infertility & Secondary infertility & \\
\hline \multirow[t]{2}{*}{ A } & $<35$ & 8 & 11 & 5 & 2 & 26 \\
\hline & $\geq 35$ & 6 & 10 & 5 & 2 & 23 \\
\hline \multirow[t]{2}{*}{ B } & $<35$ & 8 & 10 & 5 & 3 & 26 \\
\hline & $\geq 35$ & 5 & 10 & 6 & 2 & 23 \\
\hline \multirow[t]{2}{*}{$\mathrm{C}$} & $<35$ & 9 & 12 & 4 & 1 & 26 \\
\hline & $\geq 35$ & 4 & 7 & 7 & 5 & 23 \\
\hline \multirow[t]{2}{*}{ D } & $<35$ & 5 & 9 & 8 & 4 & 26 \\
\hline & $\geq 35$ & 3 & 8 & 8 & 4 & 23 \\
\hline
\end{tabular}

Table IV. Complete hatching (until day 7) in the different subgroups.

\begin{tabular}{|c|c|c|c|c|c|c|}
\hline \multirow[b]{2}{*}{ Groups } & \multirow[b]{2}{*}{ Age (years) } & \multicolumn{2}{|c|}{ No. of complete hatching } & \multicolumn{2}{|c|}{ No. of no or partial hatching } & \multirow[b]{2}{*}{ Total } \\
\hline & & Primary infertility & Secondary infertility & Primary infertility & Secondary infertility & \\
\hline \multirow[t]{2}{*}{ A } & $<35$ & 3 & 5 & 10 & 8 & 26 \\
\hline & $\geq 35$ & 2 & 5 & 9 & 7 & 23 \\
\hline \multirow[t]{2}{*}{ B } & $<35$ & 6 & 7 & 7 & 6 & 26 \\
\hline & $\geq 35$ & 2 & 4 & 9 & 8 & 23 \\
\hline \multirow[t]{2}{*}{$\mathrm{C}$} & $<35$ & 8 & 12 & 5 & 1 & 26 \\
\hline & $\geq 35$ & 3 & 7 & 8 & 5 & 23 \\
\hline \multirow[t]{2}{*}{ D } & $<35$ & 5 & 9 & 8 & 4 & 26 \\
\hline & $\geq 35$ & 2 & 8 & 9 & 4 & 23 \\
\hline
\end{tabular}

\section{Discussion}

Despite the rapid development of IVF and ICSI, the implantation rate of embryos remains relatively low. It has been indicated that only $15 \%$ of embryos were successfully transplanted into the uterine cavity in the 1990s (24). Even if a normal chromosome embryo has good developmental potential, it may be unable to grow successfully because of failure to hatch (25). Embryo implantation is affected by numerous factors, including uterine endometrial receptivity, operation of transplantation technology, and embryo hatching ability (26). Selective application of LAH in ART may enhance hatching ability. Since hatching ability plays an important role in the process of embryonic development, the basic conditions that ensure the success of a hatched embryo include that the ZP exhibits good elasticity to become thin with the expansion of the blastocyst (27). Thus, a potential mechanism to improve embryo implantation ability may be technological assurance of embryos at an earlier stage of hatching and early contact with the endometriium. ZP thinning may accelerate nutrient exchange between the liquid culture and embryo, and may promote embryonic development and blastocyst formation $(28,29)$.
Although vitrification technology has been previously developed, it has not been promoted. Studies on the effect of LAH on the cycle of FET have focused more on programme freezing (9). The vitrification process can increase embryo zona pellucida hardness and affect hatching compared with programmed freezing. Thus, patients who use frozen-thawed embryos benefit from LAH. Most of the current literature regarding LAH measures compares the embryo implantation and clinical pregnancy rates, and when the patients were grouped, the results were inevitably affected by endometrial receptivity and many other factors (30). Although most of the potential factors that interfere with the implantation of the embryo have been eliminated, the embryo implantation mechanism is extremely complex. In the present study, we established a control group and observed the effect of different $\mathrm{ZP}$ circumferences of LAH on the potential of embryonic development in order to select the optimal LAH method. The results showed that the two-third zona pellucida thinned group (group D) demonstrated a significantly decreased blastocyst formation rate compared with the control group (group A). In addition, the fully hatched rates of the blastocysts in group $\mathrm{C}$ (one-half zona thinning) were significantly higher than that of group A, while the remaining experimental groups showed no 
significant difference compared with the control group. These results are consistent with those demonstrated in previous studies (1). In the subgroup of patients, there was a significant difference in the complete hatching in the different groups for women aged $<35$ years $(\mathrm{P}=0.011)$, and there was a significant difference in the complete hatching in the different groups of secondary infertility women $(\mathrm{P}=0.022)$.

The LAH drilling method is less time-consuming than the ZP thinning method. However, previous findings have shown that if the drilling is extremely small, it causes blastocyst hatching to be incarcerated. By contrast, when the drilling is extremely large, some blastomeres in the embryos may be lost before they are closely connected (31). Therefore, many centres favour zona pellucida thinning with $\mathrm{AH}$. However, findings regarding the size of the thinned area of the zona pellucida are inconclusive. The reasons for this include, the difference in $\mathrm{AH}$ method and technology, the difference in experimental design, the difference in freezing method (programmed freezing or vitrification), and patient characteristics.

In the past, limited data were reported on the final results of the blastocysts in vitro after AH (27). In the present study, we employed vitrified-warmed sister embryos of grade I and II and performed zona thinning by ablating one-quarter, onehalf or two-thirds of the ZP circumference. The embryos were cultured using an in vitro method to observe the embryonic development potential. The results of the present study showed that the blastocyst formation rates of the four groups were $71.43 \%$ (control group), $67.35 \%$ (quarter area zona thinning), $65.31 \%$ (half area zona thinning), and $51.02 \%$ (two-thirds area zona thinning). These results showed that the blastocyst formation rate in two-thirds area zona thinning group was lower than that in control group $(\mathrm{P}=0.038)$. The random grouping of sister embryos in the same patient was performed to eliminate the difference between individuals and may reflect the effect of the laser-assisted ZP thinning in the developmental potential of embryos. However, whether the different thinning areas in the sister embryos of the same patient influence the hatching rate remains to be determined. The current study elaborated that the one-half zona pellucida thinning method significantly improved the blastocyst completely hatched rate compared to the control group, particularly with women aged $<35$ years or in women with secondary infertility. This result may have a high value in clinical application. The data of the present study are small scale, and therefore more studies are required to confirm the results.

\section{Acknowledgements}

The present study was supported by the Shandong Provincial Medical and Health Science and Technology Development Project, China (grant no. 2015WS0377) and the Shandong Provincial Natural Science Foundation, China (grant no. ZR2014HP026).

\section{References}

1. Hiraoka K, Hiraoka K, Horiuchi T, Kusuda T, Okano S, Kinutani $\mathrm{M}$ and Kinutani K: Impact of the size of zona pellucida thinning area on vitrified-warmed cleavage-stage embryo transfers: a prospective, randomized study. J Assist Reprod Genet 26: 515-521, 2009.
2. Andersen AN, Goossens V, Ferraretti AP, Bhattacharya S, Felberbaum R, de Mouzon J, Nygren KG; European IVF-monitoring (EIM) Consortium; European Society of Human Reproduction and Embryology (ESHRE): Assisted reproductive technology in Europe, 2004: results generated from European registers by ESHRE. Hum Reprod 23: 756-771, 2008.

3. Carroll J, Depypere H and Matthews CD: Freeze-thaw-induced changes of the zona pellucida explains decreased rates of fertilization in frozen-thawed mouse oocytes. J Reprod Fertil 90: 547-553, 1990.

4. Hsieh YY, Huang CC, Cheng TC, Chang CC, Tsai HD and Lee MS: Laser-assisted hatching of embryos is better than the chemical method for enhancing the pregnancy rate in women with advanced age. Fertil Steril 78: 179-182, 2002.

5. Makrakis E, Angeli I, Agapitou K, Pappas K, Dafereras A and Pantos K: Laser versus mechanical assisted hatching: a prospective study of clinical outcomes. Fertil Steril 86: 1596-1600, 2006.

6. Primi MP, Senn A, Montag M, Van der Ven H, Mandelbaum J, Veiga A, Barri P and Germond M: A European multicentre prospective randomized study to assess the use of assisted hatching with a diode laser and the benefit of an immunosuppressive/antibiotic treatment in different patient populations. Hum Reprod 19: 2325-2333, 2004.

7. Ng EH, Naveed F, Lau EY, Yeung WS, Chan CC, Tang OS and Ho PC: A randomized double-blind controlled study of the efficacy of laser-assisted hatching on implantation and pregnancy rates of frozen-thawed embryo transfer at the cleavage stage. Hum Reprod 20: 979-985, 2005.

8. Sifer C, Sellami A, Poncelet C, Kulski P, Martin-Pont B, Bottero J, Porcher R, Cedrin-Durnerin I, Hugues JN and Wolf JP: A prospective randomized study to assess the benefit of partial zona pellucida digestion before frozen-thawed embryo transfers. Hum Reprod 21: 2384-2389, 2006.

9. Petersen CG, Mauri AL, Baruffi RL, Oliveira JB, Felipe V, Massaro FC and Franco JG Jr: Laser-assisted hatching of cryopreserved-thawed embryos by thinning one quarter of the zona. Reprod Biomed Online 13: 668-675, 2006.

10. Gabrielsen A, Agerholm I, Toft B, Hald F, Petersen K, Aagaard J, Feldinger B, Lindenberg S and Fedder J: Assisted hatching improves implantation rates on cryopreserved-thawed embryos. A randomized prospective study. Hum Reprod 19: 2258-2262, 2004.

11. Balaban B, Urman B, Yakin K and Isiklar A: Laser-assisted hatching increases pregnancy and implantation rates in cryopreserved embryos that were allowed to cleave in vitro after thawing: a prospective randomized study. Hum Reprod 21: 2136-2140, 2006.

12. Ge HS, Zhou W, Zhang W and Lin JJ: Impact of assisted hatching on fresh and frozen-thawed embryo transfer cycles: a prospective, randomized study. Reprod Biomed Online 16: 589-596, 2008.

13. Valojerdi MR, Eftekhari-Yazdi P, Karimian L and Ashtiani SK: Effect of laser zona pellucida opening on clinical outcome of assisted reproduction technology in patients with advanced female age, recurrent implantation failure, or frozen-thawed embryos. Fertil Steril 90: 84-91, 2008.

14. Martins WP, Rocha IA, Ferriani RA and Nastri CO: Assisted hatching of human embryos: a systematic review and meta-analysis of randomized controlled trials. Hum Reprod Update 17: 438-453, 2011.

15. Blake DA, Forsberg AS, Johansson BR and Wikland M: Laser zona pellucida thinning - an alternative approach to assisted hatching. Hum Reprod 16: 1959-1964, 2001.

16. Mantoudis E, Podsiadly BT, Gorgy A, Venkat G and Craft IL: A comparison between quarter, partial and total laser assisted hatching in selected infertility patients. Hum Reprod 16: 2182-2186, 2001.

17. Debrock S, Peeraer K, Spiessens C, Willemen D, De Loecker P and D'Hooghe TM: The effect of modified quarter laser-assisted zona thinning on the implantation rate per embryo in frozen/vitrified-thawed/warmed embryo transfer cycles: a prospective randomized controlled trial. Hum Reprod 26: 1997-2007, 2011

18. Puissant F, Van Rysselberge M, Barlow P, Deweze J and Leroy F: Embryo scoring as a prognostic tool in IVF treatment. Hum Reprod 2: 705-708, 1987.

19. Cooper TG, Noonan E, von Eckardstein S, Auger J, Baker HW, Behre HM, Haugen TB, Kruger T, Wang C, Mbizvo MT, et al: World Health Organization reference values for human semen characteristics. Hum Reprod Update 16: 231-245, 2010. 
20. Kowalik A, Palermo GD, Barmat L, Veeck L, Rimarachin J and Rosenwaks Z: Comparison of clinical outcome after cryopreservation of embryos obtained from intracytoplasmic sperm injection and in-vitro fertilization. Hum Reprod 13: 2848-2851, 1998.

21. Aytoz A, Van den Abbeel E, Bonduelle M, Camus M, Joris $\mathrm{H}$, Van Steirteghem A and Devroey P: Obstetric outcome of pregnancies after the transfer of cryopreserved and fresh embryos obtained by conventional in-vitro fertilization and intracytoplasmic sperm injection. Hum Reprod 14: 2619-2624, 1999.

22. Hu Y, Maxson WS, Hoffman DI, Ory SJ and Eager S: A comparison of post-thaw results between cryopreserved embryos derived from intracytoplasmic sperm injection and those from conventional IVF. Fertil Steril 72: 1045-1048, 1999.

23. Hiraoka K, Fuchiwaki M, Hiraoka K, Horiuchi T, Murakami T, Kinutani M and Kinutani K: Zona pellucida removal and vitrified blastocyst transfer outcome: a preliminary study. Reprod Biomed Online 15: 68-75, 2007.

24. Edwards RG: Clinical approaches to increasing uterine receptivity during human implantation. Hum Reprod 10 (Suppl 2): 60-66, 1995.

25. Huisman GJ, Fauser BC, Eijkemans MJ and Pieters MH: Implantation rates after in vitro fertilization and transfer of a maximum of two embryos that have undergone three to five days of culture. Fertil Steril 73: 117-122, 2000.
26. Kutlu P, Atvar O and Vanlioglu OF: Laser assisted zona thinning technique has no beneficial effect on the ART outcomes of two different maternal age groups. J Assist Reprod Genet 27: 457-461, 2010.

27. Cohen J: Assisted hatching of human embryos. J In Vitro Fert Embryo Transf 8: 179-190, 1991.

28. Malter HE and Cohen J: Blastocyst formation and hatching in vitro following zona drilling of mouse and human embryos. Gamete Res 24: 67-80, 1989.

29. Hershlag A and Feng HL: Effect of prefreeze assisted hatching on postthaw survival of mouse embryos. Fertil Steril 84: 1752-1754, 2005.

30. Debrock S, Spiessens C, Peeraer K, De Loecker P, Willemen D and D'Hooghe TM: Higher implantation rate using modified quarter laser-assisted zona thinning in repeated implantation failure. Gynecol Obstet Invest 67: 127-33, 2009.

31. Edi-Osagie EC, Hooper L, McGinlay P and Seif MW: Effect(s) of assisted hatching on assisted conception (IVF \& ICSI). Cochrane Database Syst Rev (4): CD001894, 2003. 